\title{
SÃO PAULO NO CONTEXTO DA GLOBALIZAÇÃO*
}

\author{
Luiz Eduardo W. Wanderley
}

Em estudo anterior (Wanderley: 2003), foram feitas algumas distinções entre três processos históricos: mundialização, internacionalização e globalização. Amplio, no presente texto, o significado de globalização, acrescentando as reflexões de outros autores, e incorporando partes do referido trabalho.

Com fundamento privilegiado na denominada globali-zação econômica, confrontando o pensamento de diversos autores sobre o tema da globalização e suas inter-relações com a democracia, Gómez (1988: 12), inicialmente, retoma o sentido dado por Chesnais (1996), enfatizando a acepção econômica hoje prevalecente, que surgiu nos anos 1980: "em reconhecidas escolas americanas de administração de empresas, populariza-se através das obras de notórios consultores de estratégia e marketing internacional, difunde-se através da imprensa econômica e financeira especializada e, rapidamente, é assimilada pelo discurso hegemônico neoli-

\footnotetext{
* Este artigo faz parte de uma pesquisa sobre "Gestão pública e inserção internacional das cidades", desenvolvida pelo Cedec/Unesp/FGV/PUC-SP.
} 
beral". O termo, nas visões mais apologéticas, está vinculado às grandes corporações multinacionais sediadas nos centros do capitalismo mundial (Estados Unidos, Europa Ocidental e Japão). Nas palavras de John K. Galbraith, "globalização [...] não é um conceito sério. Nós, os americanos, o inventamos para dissimular a nossa política de entrada econômica nos outros países" (apud Batista, 2000: 58). Nessa perspectiva, para a corrente dos críticos radicais dessa modalidade globalizadora, ela não é um fenômeno que decorreu, naturalmente, dos avanços do modo de produção capitalista, mas uma política deliberada a qual vem sendo formulada e organizada por governos dos países ricos, empresas multinacionais, agências internacionais, com apoio ostensivo da mídia mundial, e que culmina na orientação norteadora do "pensamento único" e das tendências ao que se considera uma "ditadura do mercado".

Com base nos argumentos de distintos analistas, ainda 174 com acento no plano econômico, Gómez (apud Batista, 2000: 21) comenta: "A partir de uma visão mais abrangente, essas reflexões encaram a globalização da economia capitalista como a resultante de mutações aceleradas e profundas operadas nas últimas décadas em diversos âmbitos: tecnológico (microeletrônica, processamento de informações e telecomunicação por satélite, que permitem o incremento do volume da velocidade das informações e reduzem os custos de comunicação e de transporte); político (decisões governamentais de ajuste estrutural baseado na liberalização e desregulamentação dos mercados de bens, serviços e fatores de produção, diretrizes e pressões de agências internacionais e instâncias informais de geogovernança global); geopolítico (fim do comunismo); microeconômico (estratégias de investimento, produção e comercialização em escala mundial de firmas industriais e financeiras submetidas à competição acirrada e livre de entraves); e ideológico (hegemonia neoliberal) (Chesnais, 1996; Adda, 1996; Gill, 1995; Cox, 1996)". 
Na mesma ótica, Vieira (2001: 98) complementa: macroeconômicas (aumento do número de novos países industrializados): ideológicas (hegemonia neoliberal).

Ampliando o conceito para outros âmbitos, Gómez traz a contribuição de Laïdi (1997: 294), sublinhando a sua concordância com essa formulação

“[...] em um momento de compressão do espaço no qual os homens vivem, se movem e trocam, com todas as conseqüências que esse processo tem sobre suas consciências de pertencerem ao mundo, seja tal mundo o mercado para os mercadores, a ordem mundial para os estrategistas, o universal para os indivíduos-cidadãos. A globalização muda, assim, nossa relação com o espaço - que se amplia - e com o tempo - que se acelera. Tudo o que está em jogo, em termos de sentido, é precisamente saber como arcar simbolicamente com essa dupla mudança. Esse momento comum para todas as sociedades humanas é radicalmente incerto, de um lado, porque não implica nenhum acordo sobre a mesma visão de mundo, e, do outro, porque todos os processos que o nutrem são por definição ambivalentes. O fim da coerção geográfica é acompanhado por uma revalorização dos lugares. O pertencimento a um mesmo mundo desdobra-se em processos de distanciamento econômico e cultural sem precedentes. A simultaneidade planetária traduz-se, finalmente,em uma mundialização dos particularismos. Portanto, para pensar de maneira rigorosa a globalização, é conveniente evitar três obstáculos: vê-la sob o ângulo exclusivo de um processo de homogeneização (a síndrome McWorld, ou McDonald's, como símbolo da empresa global); reter somente os fatores de heterogeneidade; e compreender a dialética da globalização e da fragmentação recorrendo a fórmulas de efeito, fundadas, por exemplo, na oposição McWorld versus Jihad" (apud Gómez, 1996: 44). 
Estaria se constituindo uma "política da globalização" (Gill, 1995) muito imprecisa e indefinida. O que existe é uma nebulosa, "[...] constituída por um conjunto complexo e inter-relacionado de redes de influências e agências que desenvolvem uma ideologia econômica comum e realizam uma função de governança global ao injetar resultados consensuais transnacionais nos processos nacionais de tomada de decisão (Cox, 1996)" (Gómez, 1996: 27). Para ele, essas doutrinas e políticas são elaboradas e disseminadas em conclaves não oficiais (encontros anuais de Davos), de agências intergovernamentais e privadas especializadas (Comitês da OCDE, encontros dos Bancos Centrais, do Fundo Monetário Internacional e do Banco Mundial, agências privadas de avaliação) e de reuniões de cúpula dos Estados ricos (G-8). Tudo isso para constatar que, se a economia globalizada incide mundialmente, ela não condiciona por igual 176 os países, as regiões, as zonas no interior de um mesmo país, as classes, categorias e grupos sociais.

Na seqüência de seu texto, Gómez destaca duas posições sobre a globalização: a dos transformacionistas (para quem ela representa um corte radical com o passado), e os cépticos (para quem ela se afirma em sua continuidade histórica e até mesmo com precedentes similares). Para os transformacionistas, o acento recai na multiplicação e variedade inexistentes anteriormente de fenômenos supraterritoriais, com efeitos diretos no controle efetivo dos Estados sobre suas fronteiras nacionais (desterritorialização de organizações econômicas e políticas); ao lado da "explosão e difusão de identidades culturais - religiosas, de classe capitalista transnacional, de solidariedade racial, de gênero, de cultura jovem, de preferências sexuais e identidades supra-estatais no plano regional" (Gómez, 1996: 48). Estaria surgindo uma ordem mundial pós-Vestfália (ele cita Cox, Rousenau, Linklater, MacMillan), desafiadora das capacidades de autonomia e 
soberania do Estado-Nação. Mesmo que os Estados-Nação preservem seu papel de atores importantes nas relações internacionais e as fronteiras territoriais ainda conservem um lugar significativo em todos os planos, a soberania está sendo compartilhada com agências nacionais, regionais e internacionais (ele indica Held).

Já para os céticos (Gilpin, Krasner, Hirst e Thompson, são as referências indicadas), há uma rejeição da idéia de que a globalização esteja diminuindo o poder, as funções e a autoridade do Estado-Nação e, contrariamente, sustentam que sua atuação cresceu exatamente para facilitar e regular os processos de globalização.

De todas as maneiras, Gómez sinaliza que a globalização impacta a cidadania, principalmente no que concerne à identidade jurídica de direitos e deveres como se colocou na esfera ocidental; e deve considerar as "identidades socioculturais e as diferenças de grupos diversos - mulheres, pobres, anciãos, minorias raciais, étnicas, religiosas, sexuais, nacionais etc. - que se consideram oprimidos ou excluídos da cultura hegemônica, embora possuam os direitos comuns de cidadania" (Gómez, 1996: 56). Devendo-se levar em conta o pluriculturalismo, o respeito à diferença, a política do reconhecimento, eliminando-se as discriminações e as desigualdades. Nesse conjunto de mudanças mundiais, elabora-se a idéia de uma cidadania global, entendida

“[...] não apenas como a extensão na esfera das relações internacionais do conjunto dos direitos civis, políticos e sociais e suas respectivas garantias constitucionais [...] mas também como deveres morais com os outros para além das fronteiras ou obrigações com o restante da humanidade (em termos de pobreza e exclusão, de preservação do meio ambiente etc. [...] $\mathrm{E}$ isso, articulado a uma política de multiculturalismo, baseado no reconhecimento, respeito e reciprocidade das identidades - incluída a 'síndrome da identidade múltipla'-, de modo 
a evitar a oposição, exclusão e violência que têm permeado constantemente as relações internacionais no passado e ainda no presente (Scholte, 1996)" (Gómez, 1996: 57-58).

Nesse aspecto, vale trazer a colocação de Vieira (2001: 99), que, do mesmo modo, sintetiza essas posições dos transformacionistas e dos céticos, e aborda o tema da identidade no sentido de que: "isto não significa que a identidade nacional deixou de ser importante na atualidade, ou que foi absorvida por uma nova homogeneização de alcance global, seja de um hipercapitalismo sem fronteiras, seja de um cosmopolitismo de sentimentos universais e atos de solidariedade com a humanidade como um todo. Mas é inegável que a identidade nacional se tornou mais uma entre as tantas identidades que os povos hoje constroem" (Gómez, 1996, que menciona Krause e Reinwick).

Vieira acrescenta uma terceira posição, a daqueles que: "afirmam que a globalização é um mito, pois, segundo eles, a fase atual de internacionalização da economia, além de responder a um processo plurissecular imanente ao capitalismo, não é inédita, já que apresenta notáveis similitudes, em matéria de comércio, finanças, investimento direto, com a fase de internacionalização do início do século XX sob a dominação da Pax Britânica". E agrega que eles rejeitam a idéia de que as corporações multinacionais sejam efetivamente transnacionais. Além disso: "afirmam ainda que o tecnoglobalismo não é mais do que um mito que esconde a proteção e o acesso desigual dos países a inovações tecnológicas, e que os Estados nacionais, ao menos os mais poderosos, têm condições de assegurar a governança da economia mundial" (2001: 97).

Para Beck, é conveniente distinguir as noções de globalismo, globalidade e globalização. Na sua análise:

"Globalismo designa a concepção de que o mercado mundial bane ou substitui ele mesmo, a ação política; 
trata-se portanto da ideologia do império do mercado mundial, da ideologia do neoliberalismo. O procedimento é monocausal, restrito ao aspecto econômico, e reduz a pluridimensionalidade da globalização a uma única dimensão - a econômica. O que, por sua vez, ainda é pensada de forma linear e deixa todas as outras dimensões - relativas à ecologia, à cultura, à política e à sociedade civil - sob o domínio subordinador do mercado mundial" (1999: 27-28).

Globalidade significa: "já vivemos há tempos em uma sociedade mundial, ao menos no sentido de que a idéia de espaços isolados se tornou fictícia. Nenhum país, nenhum grupo pode se isolar dos outros [...] 'Mundial', na expressão 'sociedade mundial', designa então a diferença, diversidade, e 'sociedade' designa não-integração, de tal forma que se pode compreender [...] a sociedade mundial como diversidade sem unidade [...]" (Beck, 1999).

Globalização significa os processos, em cujo andamento os Estados nacionais vêem a sua soberania, sua identidade, suas redes de comunicação, suas chances de poder e suas orientações sofrerem a interferência cruzada de atores transnacionais.

Para Beck (1999), o que torna a globalidade irreversível?

1. A ampliação geográfica e a ausente interação do comércio internacional, a conexão dos mercados financeiros e o crescimento do poder das companhias transnacionais.

2. A interrupta revolução dos meios tecnológicos de informação e comunicação.

3. A exigência, universalmente imposta, por direitos humanos - ou seja, o princípio (do discurso) democrático.

4. As correntes icônicas da indústria cultural global.

5. A política mundial pós-internacional e policêntrica - em poder e número - fazem par aos governos uma quantidade 
cada vez maior de atores transnacionais (companhias, organizações não-governamentais, uniões nacionais).

6. A questão da pobreza mundial.

7. A destruição ambiental mundial.

8. Conflitos transculturais localizados.

É de relevância enfatizar que, além dos elementos já assinalados, diversos estudiosos buscam demonstrar, na esfera da globalização política, as restrições impostas por esta globalização aos Estados, principalmente aos países pobres e emergentes, na perda da soberania externa e interna, nas dificuldades de governança e governabilidade.

$\mathrm{E}$ acrescentam a globalização social, que vem alterando a estrutura nacional de classes, intensificando novas formas de desigualdades e injustiças (com a redução dos custos salariais, redução de direitos adquiridos, liberalização do mercado, despedidas em massa, desemprego estrutural); para combater a pobreza, prevalecem as medidas compensatórias que "minorem, mas não eliminem, a exclusão, já que é um efeito inevitável (e, por isso, justificado) do desenvolvimento assente no crescimento econômico e na competitividade em nível global" (Sousa Santos, 2002: 35). Sobre essa realidade, aduz os seguintes comentários: "Na América Latina, a chamada 'década perdida' sinalizou a tragicidade dessa situação, e na última década (anos 90 do século passado), mesmo tendo em vista a melhoria de certos indicadores sociais em uns poucos países, os dados concretos aferem os efeitos danosos dessa dimensão da globalização " (Wanderley, 2003: 228).

Um elemento importante, mas nem sempre valorizado suficientemente, diz respeito à globalização cultural, que se exprime, sobretudo, no avanço das tecnologias informáticas, eletrônicas e cibernéticas, no crescimento da internet; na disseminação da mídia televisiva; na divulgação preponderante de filmes, música, literatura, norte-americanos; na moda para os setores ricos; no modo de vida em geral dos 
EUA expandido como padrão universal; no uso do inglês como língua global, entre outros pontos. O debate gira em torno de se saber se ela conduz à homogeneização, ou à diferenciação, e sobre a hipótese de estar ou não emergindo uma cultura global. Para Sousa Santos, "no domínio cultural, o consenso neoliberal é muito seletivo. Os fenômenos culturais só lhe interessam na medida em que se tornam mercadorias que, como tal, devem seguir o trilho da globalização econômica" (in Wanderley, 2003: 229). No caso latino-americano, com acento no Brasil, é conhecido o fato de que existem culturas multiformes, combinando as tradições dos povos indígenas, as raízes negras africanas, as influências das imigrações multiformes, as complexas inter-relações entre a cultura popular, a cultura artística, a cultura acadêmica e a indústria cultural. E constata-se que há uma penetração, com maior intensidade, da presença de teorias e práticas culturais do chamado Primeiro Mundo, hegemoneizadas pela norte-americana, o que provoca fraturas e, simultaneamente, movimentos de defesa a protagonismo dessa imensa variedade cultural no sentido de resguardar e afirmar tradições, costumes, valores, hábitos, línguas, religiões.

Mesmo convencido de que a globalização, nas modulações que vêm mostrando, gera novas desigualdades e injustiças trágicas, além de acentuar outras já existentes, é preciso reconhecer que, em alguns de seus resultados, produz aspectos válidos, mesmo que possam ser ambivalentes e estimular ambigüidades, tais como:

- As facilidades de comunicação entre as pessoas, em tempo real, o que tem propiciado um diálogo intenso à distância. Por sua vez, cria novos espaços para troca de informações, pressões sobre governos e autoridades em geral (o caso de Chiapas foi paradigmático) (Castells, 1998), conhecimento de segredos escondidos pelos poderosos que são divulgados etc. 
- O crescimento e a rapidez no setor dos transportes, que têm facilitado a realização dos negócios, as consultas intergovernamentais e de entidades civis, as viagens em geral e o turismo em particular.

- O desenvolvimento dos meios de comunicação de massa, que dão aos usuários acesso ao que se passa no mundo, mesmo que, muitas vezes, por meio de informações fragmentadas e controladas pelos donos das cadeias transmissoras.

- Os avanços na medicina, que possibilitam o conhecimento de técnicas e remédios para um sem-número de doenças, apesar dos lobbies das empresas farmacêuticas na questão das patentes e dos altos preços dos medicamentos.

- A formação de redes entre grupos, organizações, movimentos, partidos, igrejas, abrindo canais para conhecimento mútuo e troca de experiências pessoais e coletivas.

- O intercâmbio entre professores e estudantes, trazendo um leque de aberturas para estudos e pesquisas em conjunto, enriquecedores de teorias e práticas.

\section{Globalização contra-hegemônica}

Na perspectiva de uma teorização crítica da globalização neoliberal, refuta-se a falácia do determinismo de que ela seja "um processo espontâneo, automático, inelutável e irreversível, que se intensifica e avança segundo uma lógica e uma dinâmica próprias suficientemente fortes para se imporem a qualquer interferência externa" (Sousa Santos, 2002). Para uma determinada corrente de pensamento, como ela é interpretada, é válida para os países ricos ou desenvolvidos, que procuram impor ao resto do mundo essa política globalizadora; na compreensão dos críticos, nos chamados "Terceiro e Quarto Mundos" (formados pelos países subdesenvolvidos, pobres, emergentes), ela se apresenta de modo subordinado - aos ditames das forças dominantes -, e assimétrico - gerando maiores desigualdades entre países e regiões, e dentro de cada país. Constitui-se, pois, numa globaliza- 
ção excludente (analistas nessa ótica: Chomski, Casanova, Therborn, Salama, Wallerstein), com efeitos perversos para a humanidade, ampliando a pobreza e a exclusão social (Gentili, 1999).

Nessa direção, esses autores baseiam-se em análises teóricas e em práticas potencializadoras da denominada globalização contra-hegemônica, buscando alternativas concretas de uma outra configuração. Fundamentam-se nas resistências de ações coletivas globais (campanhas e movimentos que irrompem por ocasião de eventos realizados por agências internacionais e instituições mundiais, tais como as citadas OMC, BID, Davos, G-8 etc.); se algumas entidades (Anistia Internacional, World-Wide Fund for Nature, Friends of Earth, Greenpeace, e outras) já agiam como lobbistas e trazendo protestos de impacto, ativistas protestam contra empresas como a Monsanto, McDonalds, Exxon, Nike.

Para exemplificar com dados dessas manifestações no plano mundial, vale relembrar dos 50 mil manifestantes protestando contra a OMC, em Seattle (1999), com papel destacado das ONGs, cujas reivindicações foram precedidas de reuniões e articulações (houve um manifesto, assinado por 1.200 ONGs de 87 países, via internet, articulado por Global Trade Watch e Observatoire de la Mondialization). Esse Manifesto continha itens referentes à: defesa de cláusulas sociais e ambientais; exclusão da saúde e da educação da liberalização dos serviços; exclusão dos remédios essenciais das patentes; perdão da dívida externa; agricultura (proteção dos pequenos e médios agricultores contra a concorrência externa, defesa do meio ambientes etc.); segurança alimentar; adoção do princípio de precaução para a liberação de produtos que possam afetar a saúde ou o meio ambiente (pontos extraídos da síntese preparada por Vieira, 2001: 106-107). Esse sociólogo destaca, também, outras manifestações. A Conferência Internacional sobre Alternativas à Globalização (novembro de 1998, nas Filipinas); 
as manifestações em Davos (fevereiro de 1999), lideradas pela Associação Mundial de Povos contra a Mundialização - AMP, e a Associação pela Taxação das transações Financeiras em Apoio aos Cidadãos - ATTAC, denunciando a "globalização que mata" e o "culto ao mercado". Para os organizadores, a globalização é "a centralização do poder e das riquezas nas mãos de poucos global leaders e, para um número cada vez maior de pessoas, exclusão, pobreza e miséria" (Vieira, 2001: 108). A manifestação contra a realização da reunião conjunta FMI/Banco Mundial (16 de abril de 2000), em Washington. Nela, as ONGs, agrupadas numa coalizão denominada Mobilização Global pela Justiça, denunciaram "a perversidade do sistema financeiro mundial que empobrece os trabalhadores de todo o mundo, destrói as florestas tropicais, estimula o trabalho forçado, obriga os países pobres a desviar recursos de investimentos sociais básicos para pagar a dívida externa (The New York Times, 184 17/04/2000)" (Vieira, 2001: 108). Na seqüência, houve o protesto em Praga (26 de setembro de 2000), pedindo o fechamento do FMI. Para Boaventura de Sousa Santos, "os protestos contra a (desordem neoliberal global, por ocasião da reunião anual do Banco Mundial e do Fundo Monetário Internacional em Praga, constituíram mais uma afirmação vigorosa de que as lutas democráticas transnacionais já são hoje um pilar importante do sistema político internacional e de que o seu impacto repercute tanto nas políticas nacionais como nas locais" (2001: 109). Outros protestos coletivos aconteceram em Montreal, Melbourne, Genebra, Praga, Nice, Nápoles, Gênova (300 mil manifestantes, na reunião do G-8), Cancun e Porto Alegre, entre outras cidades. Num sentido diferenciado, é de se recordar da formação do G-20, que envolveu os principais países do Terceiro Mundo, com atuação especial do Brasil.

Nesse espectro de iniciativas, cabe uma referência particular ao Fórum Social Mundial. Idealizado, no início, como 
um encontro anti-Davos, de resistência ao neoliberalismo e passagem para uma etapa propositiva, ele acontece em 2000, na cidade de Porto Alegre, firmando um "Acordo de Cooperação" entre a Associação Brasileira de organizações Não-Governamentais - Abong, Ação pela Tributação das Transações Financeiras em Apoio aos Cidadãos - Attac; Comissão Brasileira Justiça e Paz - CBJP; Associação Brasileira de Empresários pela Cidadania - Cives; Central Única dos Trabalhadores - CUT; Instituto Brasileiro de Análises Sócio-Econômicas - Ibase; Centro de Justiça Global - CJG; Movimento dos Trabalhadores Rurais Sem Terra - MST. No geral, o Fórum busca "a identificação de caminhos e propostas mobilizadoras para manifestações e ações concretas da sociedade civil". Seu lema "Um outro mundo é possível" diz bem de seu desiderato. Progressivamente, organizou-se o Conselho Internacional, ao lado dos Comitês Organizadores nacionais, que aprovou uma Carta de Princípios. Ela definia o FSM como "um espaço aberto de encontro" (não é, portanto, uma organização, entidade, instituição ou rede). Ele é delimitado politicamente como espaço "de entidades e movimentos da sociedade civil que se opõem ao neoliberalismo e ao domínio do mundo pelo capital e por qualquer forma de imperialismo". Suas propostas "contrapõem-se a um processo de globalização comandado pelas grandes corporações multinacionais e pelos governos e instituições internacionais a serviço de seus interesses, com a cumplicidade de governos nacionais". Os Encontros do FSM têm um caráter não deliberativo. O FSM "não se constitui em instância de poder, a ser disputado pelos participantes de seus encontros". O FSM é: um espaço "plural e diversificado, não confessional, não governamental e não partidário; [...] reúne e articula somente entidades e movimentos da sociedade civil de todos os países do mundo; [...] será sempre um espaço aberto ao pluralismo e à diversidade de engajamentos e atuações; [...] poderão ser convidados a participar, em caráter pessoal, go- 
vernantes e parlamentares que assumam (seus) compromissos" (trecho extraído de Correa Leite, 2004).

"Por ocasião do II FSM, dentre as inúmeras propostas surgidas, podem-se mencionar algumas: abolição da dívida externa dos países pobres; controle de capitais e impostos internacionais para a redistribuição de riqueza e financiamento do desenvolvimento; moratória contra a OMC para reorientar o comércio internacional; controle público sobre as empresas transnacionais; defesa dos direitos dos trabalhadores; desenvolvimento de um setor de economia solidária; reconstrução do meio ambiente e desenvolvimento sustentável; criação e extensão dos sistemas de saúde e educação públicos e universais; soberania alimentar; democratização dos meios de comunicação de massa; defesa da identidade dos povos; direitos dos emigrantes e combate ao tráfico de pessoas; desarmamento; direitos humanos integrais; novas instituições internacionais de governança global" (síntese extraída de T. Ponniah, IN: William Fisher and Thomas Ponniah, eds. Another world is possible: popular alternatives to globalization at the World Social Fórum; apud Correa Leite, 2004: 360, 361 e 362).

\section{Metrópole, megalópole, megacidade, cidade-global}

Compreender, classificar e definir o gigantismo que caracteriza muitas cidades do mundo tem sido objeto de análise de estudiosos das mais variadas perspectivas teóricas, que acentuam um ou outro elemento da sua configuração. As tentativas nesse sentido cobrem um espectro ora descritivo, ora interpretativo. As próprias denominações que foram e vêm sendo utilizadas constituem um testemunho eloqüente das dificuldades e complexidade existentes para a sua identificação: "grandes cidades", "metrópoles", "megalópoles", "cidades-regiões", "zonas metropolitanas”, "conurbação", "cidades-globais" etc. 
Alguns privilegiam os critérios espacial (um espaço geograficamente determinado) e demográfico (concentração de habitantes); outros privilegiam os indicadores econômicos (PIB, atividades financeiras, etc.) e sociopolíticos (peso que elas exercem, por suas atividades de gestão e de informação, nas relações nacionais e internacionais etc.). Dois critérios "clássicos" foram o da urbanização e da industrialização. Nas últimas décadas, um componente básico deriva dos processos de globalização e seus impactos nas cidades.

Estudos apontam que o termo "megalópole" foi criado pelo geógrafo francês Jean Gottmann, ao qualificar a área metropolitana que se estende sobre 700 quilômetros de Boston a Washington, no decorrer dos anos cinqüenta do século passado; e adquiriu disseminação no uso dado pelo ensaísta norte-americano Lewis Mumford que denunciava o gigantismo da megalópole considerada, para ele, como a última etapa do desenvolvimento urbano. A palavra ganhou fortuna entre especialistas, jornalistas e políticos. Nos anos 1980, por iniciativa de Philippe Haeringer (2000), pesquisador em Orstom, foi estabelecido um grupo de trabalho sobre a megalopolização do mundo, e, com importância para a nossa pesquisa, mostra a diversidade das situações urbanas e que ela não conduz para uma uniformização das paisagens e dos modos de vida. Os prefixos "mega" ou "mégalo" tem um emprego equivalente: extraído do grego "megalou" (genitivo de "megas").

Para Moriconi-Ebrard (2000), a noção é ambígua, porque ela pode ser definida em função de dois sistemas de referência: um absoluto, outro relativo. "No primeiro caso, 'megapole' poderia designar um punhado de cidades plurimilionárias em número de habitantes. Sobre a base de um atributo arbitrário, em 1990, a ONU qualificou de 'megacidades' as aglomerações que ultrapassam 8 milhões de habitantes [...] sobre esta base estatística não se observa 
nenhuma ruptura no continuum da classificação das cidades segundo seu tamanho demográfico [...] Definir o gigantismo requer um sistema de referência. É no sentido relativo que o termo 'megapole' é empregado pelos historiadores e geógrafos, para designar as grandes cidades que, em certos períodos da história ou num espaço dado, tiveram um papel excepcional 'opondo-se notadamente ao funcionamento usual da rede de cidades pequenas e médias' [...] No sentido literal, a metrópole era a cidadade-mãe (do grego meter: mãe, e polis: cidade), quer dizer a capital, a cidade que colonizou os territórios, fundada de outras cidades [...] A 'megapole' seria pois uma metrópole que possui todas as funções de comando de um sistema territorial - ou, ao menos, da maioria. Neste caso, contrariamente à 'metrópole', 'megapole' não pode ser completada do que por um epíteto; à escala de um território, somente se poderia observar senão uma e uma única 'megapole'. A noção de gigantismo seria medida por uma acumulação 'relativa' de população, de bens, de serviços ou de funções num sistema territorial ou numa rede urbana" (Moriconi-Ebrard, 1995: 9-10). A autora postula, ainda, que, para alguns, a "megapole" vive às despensas de um hinterland, do qual ela monopoliza as riquezas, mas isto é discutível; um estudo mundial mostra, ao contrário, que o tamanho de uma "megapole" está correlacionado ao efetivo de população urbana de seu hinterland (Moriconi-Ebrard, 1995: 10).

Poder-se-ia agregar o conceito de metápolis (Ascher, 1995), ou metametrópoles, no qual se acentua que as cidades são um conglomerado de espaços (de mobilidades, travessias, conflitos etc.). Nessa obra, analisa-se o planejamento urbano nas interpretações liberais e marxistas; e comentamse as teses de contestação do urbanismo moderno (concepções pós-modernistas, de caráter descontínuo, caótico, fragmentário; aquelas conduzidas pelo mercado, e aquelas de encarar as cidades como sistemas complexos). 
E um outro, que alguns autores (Castells e Hall, 1996) designam por tecnópolis, cidades nas quais se articulam desenvolvimento, ciência e tecnologia, e parcerias entre o setor privado e o setor público. "Os autores constroem uma tipologia de tecnópolis enquanto formas de concentração territorial específica e inovações tecnológicas, com potencial para gerar sinergia científica e produtividade" (Cavalcanti Limena, 1996). São contemplados três tipos: complexos industriais de alta tecnologia (por exemplo: o Slicon Valley); "cidades da ciência" (por exemplo: Tsukuba e Kansai); desenvolvimento econômico baseado em indústrias de alta tecnologia (por exemplo: Sophia-Antipolis, na França, Cambridge, na Inglaterra, e Hsinchu, em Taiwan).

\section{O debate sobre as chamadas cidades-globais}

A seguir, trago as contribuições de distintos estudiosos sobre essa polêmica questão. Ancorados em pressupostos diferenciados, o uso da terminologia cidade-global é proposta por Castells e Sassen, ainda que com matizes e acentos nem sempre convergentes, e Castells, enfatizando que ele não é um conceito unívoco, pois é condicionado por fatores históricos, espaciais e institucionais. Centrando o foco na cidade de São Paulo, Rolnik agrega comentários convergentes com essa orientação, mas aduzindo as especificidades derivadas de nossa tradição na análise das questões urbanas e ênfase na cidade-dual; Frúgoli Jr. concorda genericamente, citando comentários nessa direção; Bógus e Véras dizem como São Paulo concentra as polaridades das cidades mundiais; e Whitaker Ferreira apresenta argumentos críticos discordantes de que São Paulo seja uma cidade-global, inclusive dizendo que se trata de um debate ideológico.

Sassen (2000), em seu celebrado livro no qual denominou um conjunto delas de cidades globais, faz um destaque para São Paulo. 
"Trata-se de uma rede mundial de 20 a 25 metrópoles, que vão de Bombaim a Sidney, de Toronto a São Paulo, de Tókio a Londres, passando por New York, Paris ou Frankfurt. Essas cidades não são simplesmente, como as grandes metrópoles do passado, importantes capitais regionais; elas são, ao mesmo tempo, postos de comando da economia mundial, acolhendo as direções das multinacionais, funcionando como imensos laboratórios de inovação tecnológica e financeira, e concentrando os principais mercados de capitais internacionais [...] As cidades globais são, pois, aquelas que, além de uma infra-estrutura tecnológica excepcional, abrigam uma vasta economia intermediária de serviços altamente especializados - publicidade, contabilidade, assistência jurídica, consultoria, finanças, engenharia, arquitetura -, que sustentam e facilitam o trabalho das empresas. [...] As atividades terciárias superiores exercem assim uma influência de peso sobre a situação econômica e social das cidades. [...] A cidade global adquire sentido por sua pertença a uma rede urbana que representa, de alguma maneira, o centro nervoso da economia global. E a mundialização multiplicou, de tal modo, o volume das transações entre as grandes metrópoles mundiais que se pode perguntar, com efeito, se elas não fazem parte de um vasto e único sistema urbano. No seio do qual as cidades são mais complementares do que concorrentes" (apud Nathalie Robatel, 2000: 26-27).

Em sua visão, nesse novo contexto, para Sassen elas se transformam em cidades duais, por um lado, gerando uma polarização econômica na organização do trabalho, "que refletem uma baixa de ofertas de emprego e a bipolarização na repartição das rendas e no emprego dos trabalhadores" (Sassen, apud Nathalie Robatel, 2000: 39). Dois outros fatores contribuíram para essa bipolarização: o primeiro, pela enorme oferta de empregos de baixo salário, ou para 
o enriquecimento dos mais ricos, ou por necessidades de residência e de comércio, com: "[...] a multiplicação do número de restaurantes, de hotéis e de boutiques de luxo, das lavanderias de estilo francês, e de outros serviços de consumo da mesma natureza, que ornam as novas paisagens urbanas. Existe, pois, uma contínua necessidade de serviços industriais de baixo salário, mesmo no setor de finanças e de produtos de serviço especializado" (Sassen, apud Nathalie Robatel, 2000: 39). Ela aponta, ainda, a degradação do setor manufatureiro, o declínio da sindicalização e dos salários, em benefício de ateliês de exploração e de trabalhos a domicílio, geralmente subpagos. Por outro lado, ela enfatiza a polarização social, pelo desenvolvimento em um pólo de escritórios luxuosos e residências, num quadro de um mercado imobiliário internacional, e no outro pólo, nos centros das cidades houve um agravamento e uma concentração da pobreza material e da angústia psíquica. Indica o fenômeno da "gentrificação", inicialmente concebido como a reabilitação de imóveis decadentes dos centros urbanos e sua ocupação pelas classes médias vindas do exterior das cidades. Já nos anos 1970 e 1980, ela adquiriu uma significação mais ampla, ligada aos processos de reestruturação espacial, econômica e social. Surgem trabalhos industriais pagos em domicílio e trabalhos domésticos não assalariados, sobretudo para os imigrantes. Porém, os domicílios urbanos e suburbanos das classes médias podem se tornar locais de trabalhos domésticos pagos (amas de crianças e mulheres que trabalham em casas uma vez por semana) e trabalho profissional assalariado (elaboração de textos, trabalhos freelance etc.).

Para Castells, que sustenta as idéias de uma "revolução informacional" e da "sociedade em rede", as cidades adquirem um novo perfil com as injunções que incidem sobre as cidades: 
"A incapacidade de o Estado-Nação atender simultaneamente a essa ampla gama de exigências leva ao que Habermas denomina 'crise de legitimação', ou, segundo a análise de Richard Sennet, à 'decadência do homem público', a figura que representa as bases da cidadania democrática. Para superar tal crise de legitimação, os Estados descentralizam parte de seu poder em favor de instituições políticas locais e regionais [...] Contudo, uma vez instaurado tal processo de descentralização, os governos locais e regionais podem tomar iniciativas em nome de suas respectivas populações, e até mesmo elaborar estratégias de desenvolvimento distintas do sistema global, o que faz com que concorram diretamente com seus próprios Estados centrais [...] Os governos locais, estaduais e regionais do México, Brasil, Bolívia, Equador, Argentina e Chile beneficiaram-se da descentralização do poder e dos recursos nos anos 80 e 90, empreendendo uma série de reformas sociais e econômicas que vêm transformando a geografia institucional da América Latina. Assim, esses governos não só foram capazes de compartilhar do poder do Estado-Nação, mas tiveram condições, sobretudo, de lançar as bases de uma nova legitimidade política em prol do Estado local “ (1999b: 317-318).

Castells reproduz os termos da análise de Saskia Sassen, para introduzir outras contribuições. Daquela pesquisadora, ele cita: "A combinação de dispersão espacial e integração global criou novo papel estratégico para as principais cidades. Além de sua longa história como centros de comércio e atividades bancárias internacionais, essas cidades agora funcionam em quatro novas formas: primeira, como pontos de comando altamente concentrados na organização da economia mundial; segunda, como localizações-chave para empresas financeiras e de serviços especializados [...]; terceira, como locais de produção, inclusive a produção de inovação nesses importantes setores; e quar- 
ta, como mercados para os produtos e as inovações produzidas" (Sassen, 1991: 3-4).

Castells aponta outras grandes cidades como centros importantes, quer de serviços financeiros, quer de serviços empresariais internacionais (Chicago, Cingapura, Hong Kong, Osaka, Frankfurt, Zurique, Paris, Los Angeles, San Francisco, Amsterdã, Milão). E admite que “[...] vários 'centros regionais' estão rapidamente aderindo à rede, enquanto 'mercados emergentes' se desenvolvem por todo o mundo: Madri, São Paulo, Buenos Aires, México, Taipei, Moscou, Budapeste, entre outros" (1999a: 415-416).

Sempre argumentando que as mudanças não seguem um padrão único, universal, cujas variações dependem das características dos contextos históricos, territoriais e institucionais, o que é sempre conveniente destacar, ele aponta, com ilustrações empíricas, os impactos reais da tecnologia da informação sobre a dimensão espacial das cidades: a "centralidade da casa" (o cotidiano do domicílio eletrônico, empregos regulares para operar on-line em casa), o teletrabalho, as telecompras etc. Tudo interferindo no layout do formato urbano.

As megacidades - aglomerações enormes com mais de 10 milhões de habitantes, aí inclusa a cidade de São Paulo - concentram o melhor e o pior. Por uma parte, as funções superiores direcionais, produtivas e administrativas de todo o planeta; o controle da mídia; a política do poder; a capacidade simbólica de criar e difundir mensagens; por outra parte, as periferias; a pobreza urbana; os guetos de imigrantes; a criminalidade etc. Com suas palavras, "no entanto, o que é mais significativo sobre as megacidades é que elas estão conectadas externamente a redes globais e a segmentos de seus países, embora internamente desconectadas das populações locais responsáveis por funções desnecessárias ou pela ruptura social. [...] É esta característica distinta de estarem física e socialmente conectadas com o globo e desconectadas do 
local que torna as megacidades uma nova forma urbana" (Castells, 1999a: 429).

Um tema instigante e polêmico, tratado por David Harvey (1990) e por Castells nesta obra, diz respeito às conexões entre tempo e espaço, nas sociedades em geral e nas cidades em particular. Nessa perspectiva, espaço é entendido como o suporte material de práticas sociais de tempo compartilha$d o$. Fazendo uma interpretação entre a elite dominante e a classe dominante - o que, a meu juízo, merece uma crítica mais profunda - Castells mostra a segregação adotada por essas elites, protegidas pelos próprios preços dos imóveis. "Proponho a hipótese de que o espaço de fluxos é formado de microrredes pessoais que projetam seus interesses em macrorredes funcionais em todo o conjunto global de interações no espaço de fluxos. Esse é um fenômeno muito conhecido nas redes financeiras: decisões estratégicas importantíssimas são tomadas durante almoços de negócios, em restaurantes exclusivos ou em casas de campo nos fins de semana, enquanto se joga golfe, como nos velhos tempos. Mas essas decisões são executadas nos processos decisórios instantâneos de computadores conectados pelas telecomunicações, que podem tomar as decisões para reagir às tendências de mercado" (Castells, 1999a: 441).

Sempre apoiado em sua visão da sociedade em rede, constituída por nós interconectados, e o que ele denomina o espaço de fluxos, ele salienta (é válida a longa citação, porque exemplifica com coisas que vivenciamos no cotidiano, e tenta homogeneizar as cidades até mesmo as pequenas e médias) que: "as elites são cosmopolitas, as pessoas são locais. O espaço de poder e riqueza é projetado pelo mundo, enquanto a vida e a experiências das pessoas ficam enraizadas em lugares, em sua cultura, em sua história" (Castells, 1999a: 440). Para assinalar a distinção dessas elites no plano cultural, elas buscam "criar um estilo de vida e de projetar formas espaciais para unificar o espaço simbólico 
da elite em todo o mundo, conseqüentemente substituindo a especificidade histórica de cada local. Assim, surge a construção de um espaço (relativamente) segregado no mundo ao longo das linhas conectoras do espaço de fluxos: hotéis internacionais cuja decoração, do design do quarto à cor das toalhas, é semelhante em todo o planeta para criar uma sensação de familiaridade com o mundo interior e induzir à abstração do mundo ao redor; salas VIP de aeroportos destinadas a manter a distância em relação à sociedade nas vias de espaços de fluxos; acesso móvel, pessoal e on-line às redes de telecomunicações, de modo que o viajante nunca se perca; e um sistema de procedimento de viagem, serviços secretariais e hospitalidade recíproca que mantém um círculo fechado da elite empresarial por meio do culto de ritos similares em todos os países. Além disso, há um estilo de vida cada vez mais homogêneo na elite da informação, que transcende as fronteiras culturais de todas as sociedades: o uso regular de spas e a prática de jogging, a dieta obrigatória de salmão grelhado e salada verde com udon e sashimi como equivalente funcional japonês; a cor 'de camurça clara' da parede com o objetivo de criar a atmosfera aconchegante do espaço interno; o ubíquo laptop; a combinação de ternos e roupas esportes; o estilo de vestir unissex, e assim por diante" (Castells, 1999a: 441-442).

\section{A especificidade de São Paulo}

Atendendo ao objetivo de caracterizar ou não a cidade de São Paulo como cidade-global, e em face do exposto, trago a seguir alguns comentários nesse sentido. Para os propósitos da referida pesquisa, sugiro nomear a cidade de São Paulo, indistintamente e atendendo às especificidades de cada uma, com as seguintes terminologias. Uma grande metrópole, por seu alcance geográfico e ponto de referência regional para diversas cidades vizinhas, bem como para a área metropolitana. Como megametrópole, no sentido expresso por Rol- 
nik. E como cidade-global periférica, ou cidade-global emergente, porque determinados componentes indicados por Castells e Sassen estão presentes em São Paulo, porém eles comparecem numa situação subordinada e assimétrica, quer como potencialidades em certos aspectos (expansão do terciário, bancos internacionais, comércio mundial etc.), mas que não podem ser equiparados às cidades de Nova York, Londres e Tóquio (e mesmo outras), quer apresentando baixa intensidade em outros aspectos (sedes de conglomerados, aeroporto internacional, tecnologia avançada etc.).

São Paulo sempre foi considerada uma cidade de dinamismo especial, basicamente pelo crescimento de sua população. Vale relembrar do slogan do seu IV Centenário, que registrava que "é a metrópole que mais cresce no mundo". E sempre foi, também, uma metrópole de contrastes enormes: ora marcada por chances de mobilidade social e econômica, por agrupamentos residenciais dos ricos, ora pela expulsão da população pobre, nas periferias, cortiços, favelas etc.

Rolnik (2001) comenta que São Paulo é hoje uma das cidades-mundo do planeta, atinge pontos distantes do país, do continente, do mundo, é heterogênea, uma cidade fragmentada e lugar da competição mais selvagem e desgovernada de projetos individuais e ascensão ou sobrevivência. "Centro de produção, distribuição, gestão e logística de uma rede de empresas que atuam em mercados regionais e internacionais" (Rolnik, 2001:09), é, ela mesma, um imenso mercado: "cidade de mil povos, capital financeira, cidade conectada no mundo virtual e real das trocas, potência econômica do país, berço de movimentos sociais e lideranças políticas. No entanto, é uma cidade partida, cravada por muros visíveis e invisíveis que a esgarçam em guetos e fortalezas, sitiando-a e transformando seus espaços públicos em praças de guerra" (Rolnik, 2001: 10).

Sugestiva sua colocação de São Paulo num conjunto de expressões geradas no urbanismo, em letras de música 
popular, em filmes, em histórias de quadrinhos, em instalações artísticas, em poemas, em novelas e romances: Suburbia, Sprawling, Metrópole policêntrica, Megametrópole, Megalópole, Megacidade, Edge City, Cidade Dispersa, Cidade Global, Cidade Mundial, Cidade-Região, CidadeMundo, Cidade Informacional, Cidade-Fluxo, Rede de Cidades, Cidade-Mosaico, Cidade Caleidoscópica, Cidade Fractal, Cidade Fragmentada, Cidade Neobarroca, Cidade Neogótica, Cidade-Tela, Cidade Partida, Cidade Fechada, Cidade-Fortaleza, Cidade Sitiada, Cidade Vertical, Cidade Pós-Moderna, Cidade Mutante, Generic City, Cidade-Congestão, Cidade-Estado. E a autora se pergunta, qual se aplicaria melhor a São Paulo? E responde: "Todas. A cidade de São Paulo hoje se identifica com todas as definições e rótulos de cidades, genuinamente brasileiras ou importadas, presentes nos discursos de urbanistas, artistas, políticos, pesquisadores comunicadores. São Paulo contém as características quantitativas e qualitativas de todas essas definições" (Rolnik, 2001: 74)

Para efeitos da presente pesquisa, é importante a sua compreensão: "São Paulo é uma megacidade, participante das relações econômicas globalizadas, desempenhando funções de produção e serviços internacionais, em conexão com a vasta rede de cidades e regiões conectadas à economia global. São Paulo é uma megametrópole dispersa, que possui segmentos de cidades mundiais e globais, localizados principalmente no vetor centro-sudoeste. Fazem parte de uma rede urbana planetária, atravessada por fluxos informacionais do mercado financeiro e da rede mundializada de serviços e distribuição de mercadorias" (Rolnik, 2001: 74-75).

Em sua pesquisa sobre a centralidade de São Paulo, Frúgoli Jr. (2000), comparando as dinâmicas próprias do Centro histórico, da Avenida Paulista e da Marginal Pinheiros, em relação a esta última ele indica a prática do mercado imobiliário, e pela fala de um porta-voz da empresa Richard 
Ellis: "essa empresa também enfatiza o atendimento das necessidades dos clientes - no caso, sobretudo as grandes empresas multinacionais, que têm optado principalmente por essa área para a localização de suas sedes" (Frúgoli Jr., 2000: 221). Na mesma lógica, Frúgoli Jr. escreve: "Na outra ponta desse processo, por sua vez, está em curso uma expansão dotada de um padrão distinto de urbanização, voltado ao setor de dianteira do terciário moderno, mediado exclusivamente por regras do mercado imobiliário, num campo de consultoria, construção e instalação de empresas ligadas sobretudo a corporações multinacionais" (2000: 229).

Bógus e Véras (2000: 118), analisando a dicotomia entre o local e o global, a nova forma de territorialização e (des)territorialização - novas formas de subordinação em contextos neoliberais, apontam que:

"São Paulo concentra as polaridades das cidades mundiais, apresentando processos contraditórios, que abrangem desde as conhecidas tendências à desconcentração metropolitana, à diminuição do número de indústrias e terciarização (em especial com expansão do setor serviços, telecomunicações e informática), como as crescentes exclusão e miséria sociais, aumento do desemprego, informatização e terceirização e a configuração espacial desses processos: periferias desequipadas, crise de moradia popular (favelas, cortiços, casas precárias, homeless), condomínios fechados para estratos de renda alta e média e seu contraponto comercial: os shoppings centers".

Ainda que se possam vislumbrarna cidade de São Paulo algumas dessas mudanças assinaladas na direção de uma cidade-global emergente, existem pessoas que discordam radicalmente de caracterizá-la na condição de cidade-global, demonstrando, com dados estatísticos, que ela está muito longe desse enquadramento (Ferreira, 2003). 
Este cientista social discorda do procedimento de rotular uma cidade de "global", com base na demanda, "sem dar maior atenção às dinâmicas intra-urbanas da produção do espaço". Em contraposição às idéias de Sassen e Castells, ele procura fazer um estudo empírico para dizer que São Paulo pouco corresponde a essa expectativa de governantes, mídia e agentes imobiliários, entre outros. Comparativamente a outras cidades, seu aeroporto não participa dos 25 maiores do mundo, em classificações feitas por estudiosos das cidades-globais. Se houve uma diminuição do parque industrial na cidade, ocasionada pela (re)localização para outras cidades médias do anel macrometropolitano, os dados coletados em sua pesquisa não apontam para uma transição dela para uma economia terciária, e, muito menos, para uma "terciária de ponta”. A área total de estabelecimentos industriais na cidade não teve diminuição no período 1991 e 2000, e aumentou em 12,47\%. O que houve foi uma drástica precarização das relações empregatícias, pois, por exemplo, "o emprego informal sem carteira no setor industrial aumentou na RMSP, entre 1985 e 2000, em 130\%" (Ferreira, 2003: 134). Confrontando regiões da cidade, não surgiu um "terciário avançado" na Marginal Pinheiros, "na verdade não tem uma concentração significativa de empresas do setor, e comparativamente perde em importância para o centro de negócios surgido ainda na década de 70, a Avenida Paulista" (Ferreira, 2003;134). Das 1.187 empresas pertencentes a este setor, elas estavam localizadas em 619 endereços diferentes e não concentradas nessas regiões citadinas. Tendo em vista os bancos e companhias de seguro, empresas-modelo da economia financeira globalizada, na Marginal Pinheiros, entre os 48 dos maiores bancos atuando no Brasil somente sete têm suas sedes na região, e entre as 28 maiores companhias de seguro, somente três estão lá instaladas. Com firmeza, declara que "o fenômeno da 'cidade-global' pode mais ser, na realidade dos países subdesenvolvidos, um instrumento para a imposição 
de uma economia urbana de mercado, que exacerba mais a situação de desigualdade social, precariedade no emprego e segregação espacial" (Ferreira, 2003:136). Focando nos empreendimentos imobiliários (na Ásia, o que houve foi uma entrada maciça de investimentos externos neste setor, o que gerou um boom imobiliário sem precedentes), se lá houve uma relação clara entre a globalização da economia e processos de produção da cidade, pela presença desses capitais internacionais, "essa situação não se aplica à metrópole paulistana: nem no que tange à participação de fluxos de capitais globais na sua produção, a cidade pode ser considerada 'global' [...] o fato real é que seus agentes mais atuantes são, na sua quase totalidade, ricos e tradicionais investidores nacionais" (Ferreira, 2003:139). "Todos os grandes empreendimentos da 'centralidade terciária' da região Marginal Pinheiros, como o Centro Empresarial Nações Unidas, o World Trade Center ou o Shoping DEDD foram resultantes de iniciativas de empreendedores individuais, financiados por fundos de pensão nacionais" (Ferreira, 2003:14). Nessa óptica, o autor apenas reconhece que está ocorrendo uma pequena internacionalização do setor imobiliário.

Por que, então, existe todo um movimento para rotular a cidade como uma cidade-global? "Sem dúvida nenhuma, a resposta a essa questão é só uma: porque o discurso da 'cidade-global' interessa aos investidores imobiliários. E tal interesse não se dá unicamente porque o glamour da imagem da cidade globalizada dá status, atrai clientes e gera lucros, mas porque a promoção da 'cidade-global' legitima a canalização de recursos públicos que irão promover a valorização fundiária e imobiliária dos business discricts beneficiados e exponencializar as taxas de lucro resultantes desses empreendimentos " (Ferreira, 2003: 141). "O que ocorre na cidade é a constituição de várias 'frentes imobiliárias', todas atuando dentro desse vetor privilegiado, e disputando entre elas a captação de recursos públicos que favoreçam a valorização 
de suas áreas"(Ferreira, 2003: 142). E ele finaliza dizendo: "Porém, mais do que global, as dinâmicas que dirigem a produção da cidade de São Paulo são a representação do mais arcaico patrimonialismo, e refletem uma cidade que sequer soube superar a herança colonial de sua sociedade, por sobre a qual se aplica ideologicamente uma matriz de 'modernidade' que, a continuar assim, nunca irá responder à demanda emergencial por soluções que promovam efetivamente a cidade socialmente justa e democrática" (Ferreira, 2003:144).

\section{Luiz Eduardo W. Wanderley}

é professor titular do Departamento de Sociologia da Pontifícia Universidade Católica de São Paulo (PUC-SP)

\section{Bibliografia}

ADDA, J. 1996. La mondialisation de l'économie. Paris: La Découverte. 2 tomos.

ASCHER, F. 1995. Metápolis ou l'avenir des villes. Paris: Éditions Odile Jacob. BATISTA, Paulo Nogueira. 2000. A economia como ela é. São Paulo: Boitempo, BÓGUS, Lúcia; VÉRAS, Maura Pardini Bicudo. 2000. "A reorganização metropolitana de São Paulo: espaços sociais no contexto da globalização”. Cadernos Metrópole/Grupo de Pesquisa Pronex.São Paulo: Educ, n. 3. CASTELLS, Manuel. 1998. La era de la información. Madrid: Alianza. .1999a. A sociedade em rede. São Paulo: Paz e Terra.

1999b. O poder da identidade. São Paulo: Paz e Terra.

. HALL, P. (1996). "Technopoles: mines and foundries of the internacional economy". In: LEGATES, R. T.; STOUT, F. (orgs.). The city reader. New York: Routbedge.

CAVALCANTI LIMENA, Maria Margarida. 1996. "A crise das cidades contemporâneas - desafios do futuro”. São Paulo em perspectiva. São Paulo: Seade, v. 10 , n. 4 , outubro-dezembro.:

CORREA LEITE, José. 2004. As invenções da política. Tese de Doutorado em Ciências Sociais. São Paulo: PUC-SP..

CHESNAIS, F. 1996. A mundialização do capital. São Paulo: Xamã.

COX, R. W. 1987. Approches to world order. Cambridge: Cambridge University Press.

FEATHERSTONE, Mike. 1999. Cultura global - nacionalismo, globalização e modernidade. 3. ed. Petrópolis, RJ: Vozes. 
FERREIRA, João Sette Whitaker. 2003, São Paulo, o mito da cidade-global: ideologia e mercado na produção da cidade. VI Seminário Internacional da Unidade Temática de Desenvolvimento Urbano da Rede de Mercocidades, Buenos Aires, 3 e 4 de julho.

FRÚGOLI JR., Heitor. 2000. Centralidade em São Paulo - trajetórias, conflitos e negociações na metrópole. São Paulo: Edusp/Cortez/Fapesp.

GENTILI, Pablo (org.). 1999. Globalização excludente - desigualdade exclusão e democracia na nova ordem mundial. Petrópolis: Vozes/Clacso.

GIDDENS, Anthony. 1990. The consequences of modernity. Stanford: Stanford University Press.

1996. Para além da esquerda e da direita. São Paulo: Unesp.

GILL, S. 1995. "Globalization, Market Civilisation and disciplinary Neoiliberalism”. Millenium, Journal of International Studies. London, v. 24, n. 3.

GÓMEZ, José Maria. 1996. “A dimensão política do Mercosul. Mitos, dilemas e realidades". Praia Vermelha. Rio de Janeiro, n. 1.

. 1998. "Globalização, Estado-nação e cidadania". Contexto Internacional. Rio de Janeiro, v. 20, n. 1, janeiro-junho.

HAERINGER, Philippe. 2000. "La toile de fond: Mega versus métro, 2001. PLUS. Centre de prospective et de veille scientifique, ministère de l'Equipement, des Transports et du Logement. Paris, n. 50, décembre1999". In: ROBATEL, Nathalie (org.). "Lês villes géants à l'ère de la mondialisation". Problèmes politiques et sociaux. La Documentation Française, n. 841, 7 juillet .

HARVEY, David. (1992). A condição pós-moderna. São Paulo: Loyola.

HELD, D. 1991. "A democracia, o Estado-nação e o sistema global”. Lua Nova. São Paulo: Cedec, n. 19: .

; THOMPSON, G. 1996. Globalization in question. the international economy and the possibilities of governance. Cambridge: Polity Press.

HIRST, Paul; THOMPSON, G. 2002. Globalização em questão. Petrópolis: Vozes.

HOBSBAWN, E. 1995. A era dos extremos. São Paulo: Companhia das Letras. IANNI, Octavio. 1997. A era do globalismo. Rio de Janeiro: Civilização Brasileira.

LAÏDI, Z. 1997. La mondialisation ou la radicalisation de l'incertitude. Études. Paris, março.

LINKLATER, A. 1996. "Citizenship and sovereignity in the Post-Wesfalian State”. European Journal of International Relations. v. 2, n. 1.

MCGREW, A. G. et alii. 1992. Global Politics. Cambridge: Polity Press.

MONTERO, Paula. 1997. "Globalização, identidade e diferença". Novos Estudos Cebrap. São Paulo, n. 49, p. 47-64. 
Luiz Eduardo W. Wanderley

MORICONI-EBRARD, François. 2000. "Faux procés dês mégapoles. La lettre du PIR Villes. Paris, n. 4, janvier 1995”. In: ROBATEL, Natalie (org.). "Les villes géants à l'ère de la mondialisation”. Problèmes politiques et sociaux. La Documentation Française. n. 841, 7 juillet.

OFFE, Claus. 1989. O capitalismo desorganizado. São Paulo: Brasiliense.

OHMAE, K. 1996. O fim do Estado-Nação. Rio de Janeiro: Campus.

POLANIY, K. 1980. A grande transformação. Rio de Janeiro: Campus.

ROLNIK, Raquel. 2001. São Paulo. São Paulo: Publifolha.

ROUSENAU, J.N. 1999. Turbulence in world politics: a theory of change and continuit. Princeton: Princeton University Press.

SASSEN, Saskia. 1991. The global city. New York, Londres, Tókio. Princeton: Princeton University Press.

. 2000. Entrevista e extratos de artigos. In: ROBATEL, Natalie (org.).

"Les villes géants à l'ère de la mondialisation". Problèmes politiques et sociaux. La Documentation Française. n. 841, 7 juillet.

SOUSA SANTOS, Boaventura de (org.). 2002. A globalização e as ciências sociais. São Paulo: Cortez.

STIGLITZ, Joseph. 2002. A globalização e seus malefícios. São Paulo: Futura. VIEIRA, Listt. 2001. Os argonautas da cidadania - a sociedade civil na globalização. Rio de Janeiro: Record.

WANDERLEY, Luiz Eduardo W. 2003. "Globalização, religiões, justiça social: metamorfoses e desafios”. In: LOPES SANCHEZ (org.). Cristianismo na América Latina e no Caribe - trajetórias, diagnósticos, prospectivas. São Paulo: Paulinas. 


\section{SÃO PAULO NO CONTEXTO DA GLOBALIZAÇÃO}

LUIZ EDUARDO W. WANDERLEY

$\mathrm{O}$ artigo procura refletir sobre alguns elementos básicos dos conceitos de globalização, em sua dinâmica atual, com destaque para a globalização contra-hegemônica; e de cidade-global periférica, ou emergente, megametrópole, referenciada à cidade de São Paulo, objeto principal de estudo da pesquisa anunciada no artigo.

Palavras-chave: Globalização econômica, social, política e cultural; Globalização contra-hegemônica; Cidade-global periférica ou emergente; Megametrópole.

\section{SÃO PAULO IN THE GLOBALIZATION CONTEXT}

The article examines some basic elements of the globalization concepts (hegemonic and counter-hegemonic), on its present dynamics, and, aiming at the city of São Paulo as object of analysis, deals with such distinctions as megametropolis and peripheric or emergent global-city.

Keywords: Globalization (economic, social, political and, cultural); Counter-hegemonic globalization; Peripheric or emergent global-city; Megametropolis. 